\title{
Obituary: Stephen Edelston Toulmin
}

\author{
David Hitchcock
}

Published online: 13 May 2010

(C) Springer Science+Business Media B.V. 2010

Stephen Edelston Toulmin, who died on December 4, 2009, at the age of 87, was a seminal figure in the post-war flowering of the study of argumentation. His book The Uses of Argument (Cambridge, 1958; updated edition, 2003) introduced a new model for the layout of arguments. In place of the static monological Aristotelian categorical syllogism, with its three components of major premiss, minor premiss and conclusion, Toulmin proposed a dynamic dialectical model whose components were conceived as responses to a series of questions posed by someone challenging someone else to justify a claim $\mathrm{C}$. What do you have to go on? The answer would be one's data D, termed grounds in his later co-authored textbook (Stephen Toulmin, Richard Rieke and Allan Janik, An Introduction to Reasoning [Macmillan, 1979; second edition 1984]). How do you get there (from your data to your claim)? The answer would be one's warrant W, which in its most explicit form would be a permissive rule of inference: Data such as D entitle one to draw conclusions, or make claims, such as $\mathrm{C}$. What degree of force does your warrant confer on your conclusion? The answer would be a modal qualifier Q, such as "necessarily", "probably" or "presumably". With a qualifier other than "necessarily", under what conditions would the authority of your warrant have to be set aside? The answer would be a set of conditions of exception or rebuttal $\mathrm{R}$. What justifies your warrant? The answer would be backing $\mathrm{B}$, which Toulmin argued was specific to the field to which the claim belonged.

Toulmin's fellow philosophers did not take up his model. Indeed, reviews of his book in philosophy journals were uniformly hostile, and to this day I know of no textbook in logic or critical thinking written by a philosopher that uses his model. But the model proved apt for the field of speech communication in the United States, a discipline that had emerged from the coaching of college debaters. The "Toulmin model" is an obligatory component of textbooks in argumentation in that

D. Hitchcock $(\bowtie)$

McMaster University, Hamilton, ON, Canada

e-mail: hitchckd@univmail.cis.mcmaster.ca 
field. More recently, elements of the Toulmin model have been taken up and adapted in the field of artificial intelligence, especially in its treatment of legal reasoning and argument.

Toulmin's model was not wholly original; it incorporated, as he acknowledged, Gilbert Ryle's work on inference-licenses as well as H. L. A. Hart's treatment of defeasibility. But it brought together a number of claims about arguments that have become widely accepted: reasoning and argument involve not only support for points of view but also attacks on them ("rebuttals"); inferences to conclusions can be qualified (by "modal qualifiers"); some valid inference licenses ("warrants") are not purely formal; unstated assumptions of arguments are often better thought of as stating inference licenses ("warrants") than as being "data" or "grounds" for their conclusion; standards of reasoning ("warrants") can be field-specific; and these standards can be argued for (by "warrant-establishing arguments" that provide "backing" for a "warrant").

Toulmin proposed his model as a candid way of setting out what was involved in what he called a "micro-argument", one thrown up in the course of a larger transition from an initial statement of an unsettled problem to the final presentation of a conclusion. His book deserves re-reading as a whole for its treatment of the larger process, and in particular for his analysis (recently ably defended by Robert H. Ennis) of modal qualifiers like "probably", his contrast of "working logic" with "idealized logic", and his final call for a recasting of logic as an empirical and historical discipline that incorporates epistemology and might be called "applied logic". Both the North American informal logic movement and the theory of argumentation can be seen as exemplifying this shift.

Toulmin's book on argument should be seen in the light of his entire corpus, which reflects a distinctive and valuable intellectual orientation. After taking a degree at Cambridge in mathematics and physics, and working during World War II on the development of radar, Toulmin returned to Cambridge to do a Ph.D. in moral sciences, which he earned in 1948. From his first book, An Examination of the Place of Reason in Ethics (Cambridge, 1950), to his last, Return to Reason (Harvard, 2001), Toulmin maintained a focus on reason, reasoning and reasonableness. He set himself against all forms of abstract rationality that claimed to draw substantive conclusions without regard to history and context-from formal logic to a priori ethical principles to abstract economic theorizing. His early textbook in the philosophy of science, The Philosophy of Science: An Introduction (Hutchinson, 1953), anticipated recent work in non-formal philosophy of science. His three books on the ancestry of modern science, written with his first wife June Goodfield (The Fabric of the Heavens [Hutchinson, 1961], The Architecture of Matter [Hutchinson, 1962] and The Discovery of Time [Harper \& Row, 1965]), trace the lines of intellectual development from antiquity to the present by which the basic features of our conception of nature came to be accepted as common knowledge; The Discovery of Time, for example, tells the story of how the Earth, life and the heavens came to be understood as having a history. These studies of the ancestry of modern science enabled Toulmin to re-present in his Human Understanding, Volume I (Oxford, 1972), at greater length and in a historical frame, the central thesis of The Uses of Argument: "that, in science and philosophy alike, an exclusive 
preoccupation with logical systematicity has been destructive of both historical understanding and rational criticism" (1972, p. vii). The Abuse of Casuistry: A History of Moral Reasoning (co-authored with Albert R. Jonsen as first author; University of California Press, 1988) defended case methods in ethics by tracing the history of their use from Greek and Roman antiquity to the co-authors' own work for the National Commission for the Protection of Human Subjects of Biomedical and Behavioral Research. Cosmopolis: The Hidden Agenda of Modernity (Free Press, 1990) traces the origins of modernity from sixteenth century humanism and seventeenth century rationalism, and calls for a rapprochement between the two, one that will combine what is valuable in the rationalist ideal of a stable, self-contained formal system with a renewed appreciation for the oral, the particular, the local and the timely. Toulmin's final book, which he wanted to entitle Return to Reasonableness (personal communication), celebrates, perhaps too optimistically, a shift in many disciplines from an obsession with formal rigour inherited from seventeenthcentury rationalism to a new balance "between stubborn facts, shared values, and rival interests" (p. 213).

In person, Stephen Toulmin was an unassuming and engaging interlocutor, with an incredible wealth of historical information at his disposal. His emphasis on particularity made him a true Renaissance man. His work will live on.

Acknowledgments I am grateful to Bart Verheij and Mark Weinstein for comments on a previous draft. They are of course not responsible for any errors or blemishes that remain. 